Short Communication

\title{
Investigation of Multilayer Brazed Aluminium Corrosion Process by Electrochemical Noise
}

\author{
Longjun Guo ${ }^{1,2}$, Jihui Wang ${ }^{1,2, *}$, Wenbin $\mathrm{Hu}^{1,3}$ \\ ${ }^{1}$ Tianjin Key Laboratory of composite \& Functional Materials, School of Materials Science and \\ Engineering, Tianjin Univiversity, Tianjin, 300072, China. \\ ${ }^{2}$ State Key Laboratory of Hydraulic Engineering Simulation and Safety, Tianjin University, Tianjin \\ 300072, P R China. \\ ${ }^{3}$ Key Laboratory of Advanced ceramics and Machining Technology (Ministry of Education), Tianjin \\ Univ. Tianjin, 300072, China. \\ *E-mail: jhwang@tju.edu.cn
}

doi: $10.20964 / 2018.03 .22$

Received: 1 December 2017 / Accepted: 4 January 2018 / Published: 5 February 2018

The corrosion process of a multilayer aluminum brazed sheet AA4045/AA3003*/AA4045 in EXCO solution was investigated by electrochemical noise (EN) technique. Cluster analysis and discrete wavelet transform analysis were performed to investigate EN data. Results showed that the corrosion process can be identified by cluster analysis and the energy distribution plot (EDP) extracted from EN data. As immersion time increased, the corrosion process of the multilayer brazed sheet changed from pitting corrosion (PC) to inter-granular corrosion (IGC) to exfoliation corrosion (EC), and then back to IGC. The maximum relative energy in EDP changed from small scale to middle scale to large scale and then back to middle scale. This finding shows a good agreement with the cluster analysis result. By coupled with the EN technique and corrosion morphology, EDP and cluster analysis can be used to study the corrosion process of multilayer brazed sheet.

Keywords: Multilayer aluminum, electrochemical noise, cluster analysis, wavelet transformation, corrosion process

\section{$\underline{\text { FULL TEXT }}$}

(C) 2018 The Authors. Published by ESG (www.electrochemsci.org). This article is an open access article distributed under the terms and conditions of the Creative Commons Attribution license (http://creativecommons.org/licenses/by/4.0/). 